\title{
Prevalence of Schistosomiasis among Primary Pupils in Dawakin- Kudu Local Government Area Kano State, Nigeria
}

\author{
Abdullahi A. Minjibir ${ }^{1}$, Lurwan Mu'azu², Tinuoye, O.O. ${ }^{3}$, Muhammad Ali ${ }^{4 *}$ \\ ${ }^{I}$ Department of Pharmaceutical Technology, School of Technology, Kano State Polytechnics, Nigeria \\ ${ }^{2}$ Department of Biological Science, Federal University Gusau, Nigeria \\ ${ }^{3}$ Faculty of Computing and Applied Science, Baze University Abuja, Nigeria \\ ${ }^{4}$ Department of Microbiology, Federal University Gusau, Nigeria
}

*Corresponding Author: Muhammad Ali, Department of Microbiology, Federal University Gusau, Nigeria, Email: alimuhd4real@gmail.com

\begin{abstract}
Schistosomiasis remains one of the most prevalent parasitic worm infections and has significant economic and public health consequences. The study was aimed at determining the prevalence of Schistosomiasis among primary school pupils in Tudun-Bayero community in Dawakin-Kudu Local Government Area, Kano Northern Nigeria. A total 117 (67 boys and 50 girls) were involved in the study. Early morning urine samples from the subjects were collected and examined for the presence eggs of Schistosoma haematobium using Filtration techniques. The results showed that out of 117 urine samples examined, only 9 samples were positive which accounted for $7.7 \%$. According to the result, more males were infected $6(5.1 \%)$ than female. The highest prevalence was observed among age group 12-14 years (3.4\%) while the least prevalence was observed in age group 6-8 years (1.7\%). The prevalence of urinary Schistosomiasis based on father's occupation showed higher prevalence among farmers with $3.4 \%$, followed by those that are fishermen and artisan with $1.7 \%$ each. The statistical analysis showed that neither sex nor age had significant influence in the prevalence of the disease in the area $(p>0.05)$. There is low prevalence of $S$. haematobium in the study area.
\end{abstract}

Keywords: Kano, Prevalence, Schistosomiasis, Schistosoma haematobium

\section{INTRODUCTION}

Human schistosomiases are acute and chronic infectious diseases associated with abject poverty in 78 low and middle-income countries in the sub-tropical and tropical parts of the world where there is negligible access to potable water and adequate sanitation. The agents of etiology of these diseases are "blood-thirsty" digenetic trematodes in the genus Schistosoma $[1,2]$. Urinary schistosomiasis caused by Schistosoma haematobium is endemic in the sub-Saharan region of Africa, including in Nigeria [3, 4]. About 200 million people in some 74 countries are infected worldwide and at least 600 million are at risk of infection [5]. An estimated 120 million suffer severe consequences of the infection with an estimated annual mortality rate of about 20,000 worldwide [6]. An estimated 30 million Nigerians need to be treated annually for the disease [7]. In most endemic areas, the highest intensities of infection are found in children between 5 and 15 years of age [6]. In sub-Saharan Africa alone, it is estimated that 70 million individuals experience haematuria, 32 million difficulty in urinating, 8 million bladder-wall pathology, and 10 million major hydronephrosis from infections caused by $S$. haematobium annually. The mortality rate due to non-functioning kidneys (from S. haematobium) and haematemesis has been estimated to be 150,000 per year [8]. The above figures show that urinary schistosomiasis is an important public health problem in subSaharan Africa, second only to malaria in morbidity [9]. The distribution of the disease is focus and its effects are more common in rural areas in the tropics where the population uses natural fresh water for their domestic water supply, recreational activities, and agricultural production. Hence, disease transmission is 
contingent on the presence of infected water, the primary snail host, and contact with the human population [10]. Extreme poverty, lack of knowledge of the risks, an inadequacy or total lack of public health facilities along with the unsanitary conditions in which millions of people live their daily lives, especially in the rural areas of developing tropical countries, are all factors contributing to the risk of infection $[11,12]$.

Nigeria has the greatest number of cases of schistosomiasis worldwide [13], with about 29 million infected people, among which 16 million are children, and about 101 million people are at risk of schistosomiasis $[14,15$, 16]. Several studies indicated that the disease is found mostly among school children and transmission is usually focal. Mbata et al. [17] that is to say that the geographical distribution of the infection and of severe morbidity is restricted to a particular place. Still on the same trail, Stothard et al. [18] added that primary school children are particularly vulnerable to schistosomiasis because of their habit of playing in water, where they may contract the infection. As such, they are the ideal target group to investigate the prevalence of schistosomiasis and the data collected from this age group can be used to assess not only whether schistosomiasis threatens the health of schoolchildren, but can also be used as reference for evaluating the need for community intervention. The study was aimed at determining the prevalence of schistosomiasis among primary school pupils in Tudun-Bayero community in Dawakin-Kudu Local Government Area, Kano Northern Nigeria.

\section{Materials ANd Methods}

\subsection{Study Area}

Dawakin-kudu is one of the Local Government areas of Kano State. It is located in the southern part of the state adjacent to Kano-Zaria express with a distance of about 25 Kilometer from the state capital. Geographically, it is located at latitude $11^{0} 50^{\prime} \mathrm{N}$ and Longitude $8^{0} 35^{\prime} \mathrm{E}$. It covers an area of about $384 \mathrm{Km}^{2}$ of land. According to 2006 population census, it has a total population of 225,497 and the projected population of 313,700 as of 2016 [19]. Dawakin-kudu Local Government shares common boundaries with Kura (West), Warawa and Wudil (East), Garko (South) and Kumbotso Local Government (North). Farming, trading and dying remain the major occupations in the area. However many educated indigenes in the area are employed in the formal sector while others engaged in various trading activities.

\subsection{Sample Size Determination}

Sample size determination for this study is calculated based on the prevalence reported from initial studies carried out in the state using the following epidemiological formulae;

$\mathrm{n}=\left(\mathrm{Z}^{2} \mathrm{pq}\right) / \mathrm{d}^{2}$

Where;

$\mathrm{n}=$ Number of samples (sample size)

$\mathrm{Z}=$ Standard normal deviate at $95 \%$ confidence interval $=1.96$

$\mathrm{p}=$ Prevalence from initial studies $=8.3 \%=$ 0.083 [20]

$\mathrm{d}=$ degree of confidence at $=0.05$

$\mathrm{q}=1-\mathrm{p}=1-0.083=0.917=$

$\left([1.96]^{2} \times 0.083 \times 0.917\right) /\left[0.05^{2}\right]$

$(3.8416 \times 0.07611) / 0.0025=$

$0.2923 / 0.0025=116.95 \approx 117$

\subsection{Collection of Urine Samples}

The study population consists of 117 (67 boys and 50 girls) primary school pupils from TudunBayero Primary school in Dawakin kudu Local Government Area of Kano State. A total of 117 early morning urine samples were collected randomly from the pupil with the assistance of their teachers. About $10 \mathrm{ml}$ of urine sample was collected in a clean, dry, sterile, plastic $30 \mathrm{ml}$ universal urine bottles. Each urine sample was macroscopically observed for the presence of blood, colour and consistency. Few drops of $10 \%$ formal saline were added to each sample for preservation as described by Cheesbrough [21]. The urine samples were protected from light to avoid miracidia being hatching from the egg and then transported to the laboratory for further analysis. A simple structured questionnaire was administered to each participant in order to collect demographic data. The questionnaires were filled with the assistance of their teachers.

\subsection{Parasitological Examination of Urine Samples}

Filtration techniques were employed for parasitological examination of the urine samples as described by Muhammad et al. [22]. About $10 \mathrm{ml}$ of well-mixed urine was dispensed into the 
filtration unit of the filtration chamber. The urine was then drained through a Whatman No.1 filter paper. The filter paper was then removed and stained with the saturated Ninhydrin solution (few drops of iodine was added to enhance the staining). It was allowed to stay overnight at room temperature for the eggs to pick up the stain. It was examined under the light microscope under $\times 10$ and $\times 40$ objectives. Terminal spine eggs of $S$. haematobium were counted for each positive sample. The result was express as eggs $/ 10 \mathrm{ml}$ urine.

\subsection{Statistical Analysis}

The presence of $S$. haematobium was expressed as positive and absence was expressed as negative results in form of percentage. Data obtained from the participants were analyzed by statistical software package (SPSS version 20) using $\mathrm{X}^{2}$ test through contingency table to determine the significant differences between the data obtained.

\subsection{Ethical Approval}

The ethical approval for the study was obtained from Health Department and Local Education Authority of Dawakin Kudu Local Government Area of Kano State.

\section{Results}

\subsection{Demographic Distribution of the Subjects}

A total 117 subjects participated in the study with $67(57.3 \%)$ males and 50 (42.7\%) females of all ages. Majority of the participants were 12 to 14 years age bracket. Participant parent's occupation is mostly farming 39 subjects accounted for $33.4 \%$, followed by trading 26 subjects $(22.2 \%)$.

Table1. Demographic distribution of the subjects

\begin{tabular}{|c|c|c|}
\hline Variable & Frequency $(\mathbf{n})$ & Percentage (\%) \\
\hline \multicolumn{3}{|l|}{ Gender } \\
\hline Male & 67 & 57.3 \\
\hline Female & 50 & 42.7 \\
\hline \multicolumn{3}{|l|}{ Age (years) } \\
\hline $6-8$ & 25 & 21.4 \\
\hline $9-11$ & 43 & 36.7 \\
\hline $12-14$ & 49 & 41.9 \\
\hline \multicolumn{3}{|c|}{ Father's occupation } \\
\hline Farming & 39 & 33.4 \\
\hline Fishing & 17 & 14.5 \\
\hline Artisan & 20 & 17.1 \\
\hline Trading & 26 & 22.2 \\
\hline Civil servant & 15 & 12.8 \\
\hline
\end{tabular}

ARC Journal of Urology

\subsection{Prevalence of Urinary Schistosomiasis by Gender}

The prevalence of the infection in relation to sex is shown in Table 1. A total of 117 subjects were examined for the presence of $S$. haematobium eggs out of which 9 samples accounted for $7.7 \%$ were positive. The result shows that of 67 male urine samples examined, $6(5.1 \%)$ showed the presence of $S$. haematobium eggs while 3 out of 50 (2.6\%) female urine samples examined contained the eggs. There was no observed significant difference in infection among the sexes $(\mathrm{p}>0.05)$.

Table2. Prevalence of Urinary Schistosomiasis by Gender

\begin{tabular}{|c|c|c|c|c|}
\hline Gender & $\begin{array}{c}\text { No } \\
\text { examined }\end{array}$ & $\begin{array}{c}\text { No. } \\
\text { infected }\end{array}$ & $\begin{array}{c}\text { Prevalence } \\
(\mathbf{\%})\end{array}$ & P value \\
\hline Male & 67 & 6 & 5.1 & $.581933^{*}$ \\
\hline Female & 50 & 3 & 2.6 & \\
\hline Total & $\mathbf{1 1 7}$ & $\mathbf{9}$ & $\mathbf{7 . 7}$ & \\
\hline
\end{tabular}

Key: $*=$ result is not significant at $p<0.05, X^{2}=$ 0.3031

\subsection{Prevalence of Urinary Schistosomiasis among Age Groups}

The prevalence rate of the disease with respect to age is shown in Table 2. The result shows that the infection rate uniquely cut across all the age brackets studied although the age bracket 12 14 years contained more infection than the other age groups but still there was no observed significant difference in infection among the age groups ( $>0.05)$.

Table3. Prevalence of Urinary Schistosomiasis among age Groups

\begin{tabular}{|c|c|c|c|c|}
\hline $\begin{array}{c}\text { Age } \\
\text { (years) }\end{array}$ & $\begin{array}{c}\text { No } \\
\text { examined }\end{array}$ & $\begin{array}{c}\text { No. } \\
\text { infected }\end{array}$ & $\begin{array}{c}\text { Prevalence } \\
(\boldsymbol{\%})\end{array}$ & P value \\
\hline $6-8$ & 25 & 2 & 1.7 & $.978892 *$ \\
\hline $9-11$ & 43 & 3 & 2.6 & \\
\hline $12-14$ & 49 & 4 & 3.4 & \\
\hline Total & $\mathbf{1 1 7}$ & $\mathbf{9}$ & $\mathbf{7 . 7}$ & \\
\hline
\end{tabular}

Key: $*=$ result is not significant at $p<0.05, X^{2}=$ 0.0427

\subsection{Prevalence of Urinary Schistosomiasis based on Father's Occupation}

The prevalence of urinary schistosomiasis based on father's occupation of the subjects is presented in Table 4. In regards to that, higher prevalence of urinary Schistosomiasis was recorded among farmers with $3.4 \%$, followed by those that are fishermen and artisan with $1.7 \%$ 
each, followed by trading with $0.9 \%$, while no prevalence was recorded among those that are civil servant.

Table4. Prevalence of Urinary Schistosomiasis based on Father's Occupation of the Subject

\begin{tabular}{|c|c|c|c|c|}
\hline $\begin{array}{c}\text { Father's } \\
\text { occupation }\end{array}$ & $\begin{array}{c}\text { No } \\
\text { examined }\end{array}$ & $\begin{array}{c}\text { No. } \\
\text { infected }\end{array}$ & $\begin{array}{c}\text { Prevalence } \\
(\mathbf{\%})\end{array}$ & P value \\
\hline Farming & 39 & 4 & 3.4 & .901252 \\
\hline Fishing & 17 & 2 & 1.7 & \\
\hline Trading & 26 & 1 & 0.9 & \\
\hline $\begin{array}{c}\text { Civil } \\
\text { servant }\end{array}$ & 15 & 0 & 0.0 & \\
\hline Artisan & 20 & 2 & 1.7 & \\
\hline Total & $\mathbf{1 1 7}$ & $\mathbf{9}$ & $\mathbf{7 . 7}$ & \\
\hline
\end{tabular}

Key: $*=$ result is not significant at $p<0.05, X^{2}=$ 1.0556

\section{DISCUSSION}

Prevalence of urinary schistosomiasis among school children continues to be a major public health concern in tropical countries especially in Nigeria. The overall prevalence of urinary schistosomiasis the present study is $7.7 \%$ which can be further classified as low with respect to World Health Organization documentation on endemic communities [23]. This prevalence was lower compared to studies carried out in Ondo State Nigeria (13.8\%) [24], Benue State (46.6\%) [17] and Region of Ethiopia (24.54\%) [25]. It was also lower compared to studies conducted Swaziland (5.3\%) [26] and middle Awash Valley of Ethiopia (3.1\%) [27]. The difference in prevalence from place to place could be explained as a result of differences in environmental factors that can, in turn, lead to differences in transmission intensity [28]. The lower prevalence reported by the present study could be attributed to the integrated and costeffective approaches implemented by the Federal Ministry of Health to eliminate multiple NTDs in Nigeria including Schistosomiasis. The major factors that may be responsible for the presence of urinary schistosomiasis infection in this study area is ignorance of the infection as regard to water contact with snails infested streams and rivers, lack of basic amenities, inadequate and indiscriminate disposal of human sewage [17, 29, 30].

Finding from the present study reveals that males were more infected (6 infected) with urinary schistosomiasis than females (3 infected). This finding was in conformity with those of Abu-Zaid et al. [31]; Risikat and Ayoade, [32] and Gyuse et al. [33] who all found higher infection among male than female. Socio-cultural factors where males are mostly engaged in water- contact activities like swimming and bathing, fishing, farming and watering cattle could lead to higher exposure among males and this attributed to the higher prevalence among male subjects

Age groups 12-14 years were more prevalent in the study with occurrence rate of $3.4 \%$ and the lowest occurrence recorded among the age groups $6-8(1.7 \%)$. This finding agrees with that of Dakul et al. [34] who reported the highest prevalence $65.8 \%$ among the age group 10-14 years in Plateau State, Nigeria. Higher prevalence among this age category could be attributed to the high rate of water contact activities by the age group and their susceptibility to infection with respect to their immune response. The statistical analysis showed that neither sex nor age had significant influence in the prevalence of the disease in the area $(\mathrm{p}>0.05)$.

According to the present study, the occupation of father is associated with urinary schistosomiasis where children whose fathers are farmer were more infected (3.4\%), followed by fishing and artisanship (1.7\%) each. This finding agreed studies from Sudan [35] and Nigeria [36] where children participated in field activities with their fathers. This shows lack of awareness towards risk of urinary schistosomiasis among fathers to make their children aware of the risk of urinary schistosomiasis. A protective role of the head of the family being literate and informed on urinary schistosomiasis was reported from an earlier study in South-western Nigeria [31].

\section{CONCLUSiON}

Based on the findings of this study, there is low prevalence $(7.7 \%)$ of urinary schistosomiasis among primary school pupil in the study area. However, more male were infected than female and children of higher class (aged $12-14$ years) were more infected. Despite low prevalence of the infection in the study area, it is recommended that that schistosomiasis control program in the community should be embarked upon to educate the populace on risk factors that predispose an individual to urinary schistosomiasis and the need for proper sewage disposal, adequate provision of social amenities such as pipe borne water and toilet facilities to the study area in order to reduce the menace of the infection. 


\section{ACKNOWLEDGEMENT}

The authors wish to acknowledge to the Departments of Health and Education Dawakin - kudu Local Government Area for their support and cooperation. Thanks to Department of Biological Science, Bayero University Kano for the use of Laboratory facilities

\section{REFERENCES}

[1] Colley DG, Bustinduy AL, Secor WE, King CH. (2014). Human schistosomiasis. Lancet. 383 (9936):2253-64.

[2] World Health Organization (2017). Schistosomiasis. Fact sheet 115 updated January 2017. Available at: http://www.who.int/mediacentre/factsheets/fs11 5/en/.

[3] Chitsulo L, Engels D, Montresor A, Savioli L. (2000). The global status of schistosomiasis and its control. Acta Tropica, 77, 41-51.

[4] Ekejindu IM, Ekejindu GOC, Agbai A. (2002). Schistosoma haematobium infection and nutritional status of residents in Ezi- Anam, a riverine area of Anambra state, South-Eastern Nigeria. Nigerian Journal of Parasitology, 23, 131-138.

[5] WHO. (1995). Identification of high-risk communities for control of schistosomiasis in Africa: a multi community study. Geneva, Switzerland: World Health Organization. Social and Economic Research Reports.

[6] WHO. (1998). Guidelines for the evaluation of soil transmitted helminthiasis and schistosomiasis at community level: a guide for managers of control programmes. Geneva, Switzerland: World Health Organization.

[7] Anosike JC, Okere AN, Nwoke BE, Chukwu JU, Nwosu DC, Njoku-Tony RF, Oguwuike TU, Ezike MN, Okogun RA, Obasi CU, Ogbusu FI, Onyirioha CU, Ajero CM, Dike MU. (2003). Endemicity of vesical schistosomiasis in the Ebonyi Benue river valley, south eastern Nigeria. International Journal of Hygiene and Environmental Health, 206, 205-210.

[8] van der Werf MJ, de Vlas SJ, Brooker S, Looman CW, Nagelkerke NJ, Habbema JD, Engels D. (2003). Quantification of clinical morbidity associated with schistosome infection in sub-Saharan Africa. Acta Tropica, $86,125-139$.

[9] WHO. (1993). The control of schistosomiasis: report of the WHO Expert Committee. Geneva, Switzerland: World Health Organization. Technical Report Series.

[10] Nwosu DC, Anosike JC, Nwoke BEB, Uwaezouke JC. (2006). Epidemiological assessment of vesical schistosomiasis in Bende local government area of Abia state, Nigeria. Journal of Applied Sciences and Environmental Management, 10, 55-60

[11] Michaud CM, Gorden WS, Reich MR. (2003). The global burden of diseases due to schistosomiasis DCPP working paper. http:// www.hsph.harvard.edu/schisto.

[12] WHO. (2002). Prevention and control of schistosomiasis and soil transmitted helminthiasis. Geneva, Switzerland: World Health Organization. Technical Report Series.

[13] Hotez PJ, Asojo OA, Adesina AM. (2012). Nigeria: "Ground Zero" for the high prevalence neglected tropical diseases. PLoS Negl Trop Dis. 6:e1600.

[14] World Health Organization (2013). Schistosomiasis: progress report 2001-2011 and strategic plan 2012-2020. Geneva: WHO; 2013.

[15] Adenowo AF, Oyinloye BE, Ogunyinka BI, Kappo AP. (2015). Impact of human schistosomiasis in sub-Saharan Africa. Braz $\mathbf{J}$ Infect Dis. 19:196-205.

[16] Steinmann P, Keiser J, Bos R, Tanner M, Utzinger J. (2006). Schistosomiasis and water resources development: systematic review, meta-analysis, and estimates of people at risk. Lancet Infect Dis. 6:411-25.

[17] Mbata TI, Orji MU, Oguoma VM. (2009). High prevalence of urinary schistosomiasis in a Nigerian community. Afr J Biomed Res. 12:2.

[18] Stothard JR, French MD, Khamea IS, et al. (2009). The epidemiology and control of urinary schistosomiasis and soil-transmitted helminthiasis in schoolchildren on Unguja Island, Zanzibar. Trans R Soc Trop Med Hyg. (103):1031-44.

[19] National Population Commission (NPC) (2016). National population census result, Abuja Nigeria

[20] Dawaki S, Al-Mekhlafi HM, Ithoi I, Ibrahim J, Abdulsalam AM, Ahmed A, Sady H, Atroosh WM, Al-Areeqi MA, Elyana FN, Nasr NA, Surin J. (2016). Prevalence and risk factors of schistosomiasis among Hausa communities in Kano State, Nigeria. Rev Inst Med Trop Sao Paulo. 58:54

[21] Cheesbrough M. (2006). District laboratory practice in tropical countries, part 1. 2nd ed. Cambridge: Cambridge University Press

[22] Mohammed K, Suwaiba M, Spencer TH, Nataala SU, Ashcroft OF, NuhuA and Asiya UI (2018). Prevalence of Urinary Schistosomiasis among Primary School Children in Kwalkwalawa Area, Sokoto State NorthWestern Nigeria, Asian Journal of Research in Medical and Pharmaceutical Sciences 3(1): 110, DOI: 10.9734/AJRIMPS/2018/38623 
[23] Bala, AY, Ladan MU, Mainasara M. (2012). Prevalence and intensity of urinary schistosomiasis in Abarma village, Gusau, Nigeria: A preliminary investigation. Sci World J. 7(2):1-4.

[24] Akinneye JO, Fasidi MM, Afolabi OJ, Adesina FP (2018) Prevalence of Urinary Schistosomiasis among Secondary School Students in Ifedore Local Government, Ondo State, Nigeria. Int J Trop Dis 1:004.

[25] Deribew K, Tekeste Z, Petros B. (2013). Urinary schistosomiasis and malaria associatedanemia in Ethiopia. Asian Pac J Trop Biomed. 3(4):307-10. DOI: 10.1016/S22211691(13)60068-4.

[26] Liao CW, Sukati H, Nara T, Tsubouchi A, Chou CM, Jian JY, et al. (2011). Prevalence of Schistosoma haematobium infection among schoolchildren in remote areas devoid of sanitation in Northwestern Swaziland, Southern Africa. Jpn J Infect Dis. 64(4):322-6.

[27] Negussu N, Wali M, Ejigu M, Debebe F, Aden S, Abdi R, et al. (2013). Prevalence and distribution of schistosomiasis in Afder and Gode zone of Somali region. Ethiopia. J Glob Infect. Dis. 5:149-52.

[28] Clements ACA. Firth S, Dembele R, Garba A, Toure S, Sacko M, Landoure A, Bosque-Oliva E, Barnett AG, Brooker S, Fenwick A. (2009). Use of bayesian geostatistical prediction to estimate local variations in Schistosoma haematobium infection in western Africa. Bull World Health Organ. 87:921-929.

[29] Houmsou RS, Amuta EU, Sar TT. (2012). Profile of an epidemiological study of urinary schistosomiasis in two local government areas of Benue State, Nigeria. Intern J Med Biomed Res. 1(4):39-48.

[30] Ivoke, N, Ivoke ON, Nwani CD. (2014). Prevalence and transmission dynamics of Schistosoma haematobium infection in a rural community of southwestern, Ebonyi State, Nigeria. Trop Biomed. 31(1):77-88.

[31] Abou-Zeid AH, Abkar TA, Mohamed RO. (2013). Schistosomiasis infection among primary school students in a war zone, Southern Kordofan State, Sudan: A crosssectional study. BMC Public Health. 13:643

[32] Risikat SA and Ayoade AA (2012). Correlation analysis between the prevalence of Schistosoma haematobuim and water conditions: A case Study among the School Pupils in Southwestern Nigeria. IJRRAS. 13(1):160-5.

[33] Gyuse KI, Ofoezie IE, Ogunniyi TAB. (2010). The effect of urinary schistosomiasis on the health of children in selected rural communities of Osun State, Nigeria. J Trop Med Parasitol. 33:7-16.

[34] Dakul DA, Onwuliri COE, Anyanwu GI, Imander NG. (2001). A longitudinal study of Schistosoma haematobium infection in Quaanpan local government area of Plateau State. J,Pest.dis. vector manage. 3:225-230.

[35] Jamaneh et al. (1994). Prevalence of Schistosoma haematobium infection among school children in remote areas;

[36] Akogun OB, Obadiah S. (1996). History of Haematuria among school- Age Children for Rapid community diagnosis of urinary Schistosomiasis in Nigeria. Niger. J. Parasitol. 17:11-15

Citation: Abdullahi A. Minjibir, Lurwan Mu'azu, Tinuoye, O.O., Muhammad Ali. Prevalence of Schistosomiasis among Primary Pupils in Dawakin-Kudu Local Government Area Kano State, Nigeria. ARC Journal of Urology. 2020; 5(1):15-20. DOI: https://doi.org/ 10.20431/2456-060X.0501004.

Copyright: (C) 2020 Authors. This is an open-access article distributed under the terms of the Creative Commons Attribution License, which permits unrestricted use, distribution, and reproduction in any medium, provided the original author and source are credited. 